\title{
El texto narrativo en la clínica psicoanalítica del síntoma de aprendizaje del lenguaje: un análisis estructural
}

\author{
O texto narrativo na clinica psicanalítica do sintoma \\ de aprendizagem da linguagem: uma análise estrutural ${ }^{*}$
}

\author{
The narrative text of language learning symptom \\ in the psychoanalytical clinic: a structural analysis
}

\author{
Gláucia Grohs** \\ Universidade Federal do Rio Grande \\ do Sul, UFRGS \\ Tania Mara Sperb ${ }^{* * *}$ \\ Universidade Federal do Rio Grande \\ do Sul - UFRGS \\ Centro de Estudos da Linguagem e da \\ Interação Social - CELIS / GIDEP
}

Recibido: 15 de junio de 2010 Revisado: 2 de octubre de 2010

Aceptado: 3 de mayo de 2011

\section{Resumen}

Este artículo presenta datos de uno de los estudios desarrollados en la tesis doctoral "El texto narrativo como intervención terapéutica en problemas del lenguaje escrito en la adolescencia: el análisis estructural del texto narrativo producido en psicoterapia de orientación psicoanalítica". Se demuestra a partir de este análisis la posibilidad de utilizar el texto narrativo como instrumento de intervención y medida de resultados en investigación en psicoterapia en la clínica del adolescente que trata síntomas en el aprendizaje del lenguaje escrito.

Palabras clave: análisis estructural, narrativa, psicoterapia de orientación psicoanalítica.

\section{Resumo}

Este artigo apresenta dados de um dos estudos desenvolvidos na tese " $O$ texto narrativo como inter-

\footnotetext{
Artigo originado da tese: "O texto narrativo como intervenção terapêutica em problemas da linguagem escrita na adolescência" defendida na Universidade Federal do Rio Grande do Sul - UFGRS; Instituto de Psicologia; Programa de Pós-Graduação em Psicologia, agosto de 2009.

** Psicóloga, Mestre em Psicologia do Desenvolvimento (UFRGS), Especialista em Atendimento Clínico: ênfase psicanálise (UFRGS). Doutoranda em Psicologia. (UFRGS), Docente do Curso de Psicologia da Ultra. Dirección Postal: Avenida Cristovão Colombo 462 apartamento 603D bloco D. Bairo Floresta, Ciudade Porto Alegre, Estado Rio Grande do Sul. Email: grohs2007@gmail.com.

*** Orientadora da tese, Professor Colaborador, Programa de Pós-graduação em Psicologia, Universidade Federal do Rio Grande do Sul - UFRGS, Centro de Estudos da Linguagem e da Interação Social - CELIS / GIDEP www.psicologia.ufrgs/GIDEP
} 
venção terapêutica em problemas da linguagem escrita na adolescência” (Grohs, 2009): a análise estrutural do texto narrativo produzido em psicoterapia de orientação psicanalítica. Demonstra-se a partir desta análise, a possibilidade de se utilizar o texto narrativo como instrumento de intervenção e de medida de resultados em pesquisa em psicoterapia na clínica do adolescente que produz sintoma na aprendizagem da linguagem escrita.

Palavras-chave: análise estrutural, narrativa, psicoterapia de orientação psicanalítica.

\section{Abstract}

This article presents data of one of the studies developed in the thesis "The narrative text as therapeutic intervention in written language problems in adolescence" (Grohs, 2009): a structural analysis of the narrative text produced in psychoanalytical psychotherapy. This analysis points to the possibility of using the narrative text as an instrument of intervention and of measuring results in research in clinic psychotherapy of adolescents who present symptoms in written language learning.

Keywords: structural analysis, narrative, psychotherapy, psychoanalytical.

\section{Introdução}

A pesquisa em psicoterapia tem se desenvolvido como forma de discutir os modelos clínicos, seus processos e resultados (Ceitlin, Manfro, Jung e Cordioli, 2008). Alguns pesquisadores têm apontado as diferenças e as modificações técnicas que se tornam produtivas quando se trata de avaliar a eficácia das abordagens terapêuticas, como salientam Deakin e Nunes (2008) ao revisar as abordagens da psicoterapia psicanalítica infantil; Jardim, Oliveira e Gomes, (2005) ao abordar questões da psicoterapia na adolescência; e mesmo no caso em questão, as especificidades que se possam delimitar na clínica dos sintomas de aprendizagem da linguagem escrita, entendidas como dificuldades no processo de alfabetização.

O tratamento psicoterápico ao incidir sobre adolescentes que fazem sintoma na aprendizagem da linguagem escrita salienta a interação entre um aparato inteligente e pulsional (Paín, 1987; Kupfer, 2002; Lemos, 2007; Santiago e Castanheira, 2004) e exige do terapeuta uma atenção pontual sobre a forma que se desenvolverá o seu trabalho clínico. Em termos de desenvolvimento, estar na adolescência pressuporia uma produtividade com a linguagem escrita, minimamente já colocada. Para dar conta desta suposta falha no processo de significação operada pelo uso da linguagem, empreendeu-se o trabalho psicoterápico com um adolescente que ao chegar aos seus treze anos pouco sabia sobre o ler e escrever. A composição narrativa realizada conjuntamente com o terapeuta, tornou-se um meio de acesso a este adolescente que sintomatizou no processo de alfabetização (Cordié, 1996; Vincent, 2006; Araújo, 2002; Farias, 2007; Degenszajn, Roz e Kotsubo, 2000) através do qual o próprio sujeito pode narrar-se em seu sintoma. Para Beran \& Unoka, (2005) é possível utilizar a construção de narrativas no contexto psicoterápico, em forma de autobiografias, empreendida entre paciente e terapeuta no curso de uma sessão terapêutica, como uma das vias para trabalhar clinicamente.

A análise estrutural das composições narrativas produzidas pelo paciente adolescente ao longo do percurso terapêutico teve como objetivo definir em que medida estas composições se caracterizavam como uma narrativa a partir do referencial de Todorov (1971/2003). Esta análise a qual foi submetido um conjunto de composições em formato de música rap, tornou-se um recurso metodológico encontrado para auxiliar o terapeuta a explicitar o conteúdo e a recorrência do sintoma ao longo do processo terapêutico e, consequentemente, "mapear" a eficácia do tratamento. 


\section{Especificidades da composição narrativa na clínica do sintoma da aprendizagem da linguagem escrita}

Aquele que não sabe escrever nem ler poderia expressar através deste não as suas dificuldades em utilizar produtivamente a linguagem. 0 movimento psíquico que parte de um "negar-se a" aquisição de um sistema linguístico, faz com que o sujeito "crie" através deste não uma substituição simbólica, um sintoma, como produto psíquico que substitui a operação de aquisição do conhecimento por uma negação. Consequentemente, nos sintomas de não aprendizagem da linguagem escrita, a linguagem pouco produz como efeito de um desvelamento do próprio sujeito e nas suas relações com o mundo.

Num primeiro plano, o que se coloca no processo incial de aproximação com a linguagem escrita é da ordem do compreensão. 0 mundo, coisas e pessoas, e suas relações são intermediados por representações que se tornam símbolos e que ao se combinarem geram múltiplas possibildades de significação. Num outro plano, é necessário construir um saber que se opera através do uso da linguagem, e com ele criamos sentidos sobre nós mesmos na relação com objetos. Quando alguém falha ao iniciar este processo de aproximação, parece como que as palavras estivessem "vazias" de sentidos e não se tornassem passiveis de referir, substituir ou significar algo nas trocas com outro. Como salienta Kristeva (1969/2003), ao tratarmos sobre linguagem estamos falando sobre "demarcação, significação e comunicação". Aquele que "nega-se" ao uso produtivo da linguagem escrita - claro que não de uma forma absoluta, pois ele "fala" - dificulta para si não somente o comunicarse; mas e, principalmente, a troca de saberes sobre as coisas e sobre si mesmo, tornando-se alheio ao mundo do conhecimento. Quando recebemos na clínica de orientação psicanalítica uma criança ou adolescente que não consegue ser produtivo com a linguagem e que não demonstra nenhuma outra falha orgânica ou funcional, interpretar-se esta dificuldade pela via da inscrição do sujeito no saber. Neste sentido, o tratamento assume um lugar para o qual o sujeito possa remeter-se como um campo de reconstrução de si, acima já destacado e, também, salientado por Sousa (2004).

0 trabalho terapêutico que incide sobre a composição textual em forma de narrativas, seja em formato oral ou escrito, toma como parâmetro que a gramática da narrativa dispõe em sua estrutura uma intriga ao entrelaçar personagens e suas ações na forma como o tema é desenvolvido na história. Para Ducrot e Todorov (1998), o texto narrativo é um texto referencial que coloca uma temporalidade representada numa sequência de pelo menos três proposições. É neste encadeamento global das sequências em seu interior que se produzirá a intriga. Desta forma, o texto narrativo dimensiona o aspecto produtivo de toda composição textual. 0 texto que se "escreve" na clínica, é um texto composto na conjunção das vozes de dois atores que se interelacionam, o paciente e o terapeuta. A estrutura deste texto remete a um composto de significações que fornece seu conteúdo e que dispõe aquele que sofre e faz sintoma na angústia de seu não saber sobre o que o colocou nesta situação. Esse é o sentido pleno do fazer sintoma e que pode assumir algum sentido quando narrado para um outro que sabe de onde o escutar - o lugar do terapeuta na clínica psicanalítica. $O$ texto narrativo produzido em sessão psicoterápica cria espaço para uma produtividade significada (Eco, 1886; Kristeva,1967/1980). Produtividade é aqui compreendida não só como as próprias condições e efeitos da textualidade, mas também nos efeitos produzidos sobre o próprio sujeito ao interagir com o texto, seja ele leitor ou escritor.

Em Psicanálise, narrar-se é tratar-se. Contar a sua história passada, num tempo presente, tem o fim de reorganizar o sujeito-paciente na medida em que provoca o reposicionamento daquele que conta para aquele que escuta. Na interlocução entre tratamento e narrativa, têm-se como princípios psicanalíticos os conceitos de livre associação e atenção flutuante que sustentam a relação transferencial entre paciente e terapeuta. Como princípios narrativos nesta composição, têm-se uma história passada que é narrada por um narrador a um destinatário. E como produto desta interlocução, tem-se o texto narrativo composto entre 
esses sujeitos, que ao ser narrado no tempo presente, torna-se o material para o trabalho clínico. A característica fundamental do texto narrativo composto na clínica é a interdependência entre uma temporalidade colocada e a narratividade.

\section{Alguns aspectos sobre a estrutura do texto narrativo na concepção todoroviana}

Todorov (1971/2003) estabeleceu uma gramática das atividades simbólicas e definiu sua análise estrutural da narrativa como um aparato descritivo para entender a composição do texto narrativo, onde a personagem é um nome e a ação, um verbo. 0 estudo da articulação destes componentes na história conduz à estrutura da intriga. Para Todorov (1968/1971), a intriga mínima completa consiste na passagem de um equilíbrio para outro, e toda narrativa ideal define-se por uma situação estável (inicial), a qual uma força qualquer vem perturbar. Disso resulta um estado de desequilíbrio, sobre o qual incide a ação de outra força com sentido contrário, a fim de restabelecer o equilíbrio. Esse segundo estado de equilíbrio é semelhante ao primeiro, embora os dois nunca sejam idênticos. Consequentemente, há dois tipos de episódios numa narrativa: aqueles que descrevem um estado (de equilíbrio ou de desequilíbrio); e os que descrevem a passagem de um estado para outro.

Segundo Todorov (1971/2003), toda narrativa supõe uma sucessão das ações que não é arbitrária, mas que obedece a uma lógica na qual a uma ação corresponde um oposto e este constitui o esquema de base de toda narrativa. Como estes esquemas de base são em número limitado, é possível representar a intriga de qualquer narrativa como uma derivação deles. Reis e Lopes (1988) salientam que esta dinamicidade da narrativa, através de seus mecanismos de articulação, possibilita a análise do texto narrativo em dois planos: o da história e o do discurso, cuja articulação se complementa no ato de narração. Para os autores, as categorias da história, como personagem, espaço e ação, submetem-se a procedimentos de repre- sentação elaborados no plano do discurso: o tempo da narração e o tipo de narrador adotado. Os autores afirmam que, do ponto de vista da narratividade, uma das qualidades intrínsecas do texto narrativo é a transformação.

Todorov (1971/2003), ao considerar o aspecto transformações, distingue dois tipos como forma característica do discurso narrativo: primeiro as transformações simples (ou especificações) que modificam ou acrescentam certo operador que especifica o predicado. E segundo, as transformações complexas (ou reações), que são caracterizadas pelo aparecimento de um segundo predicado que se insere no primeiro e não pode existir independente dele. Segundo ele, são exatamente essas transformações complexas que designam as operações psíquicas no texto narrativo, ao relacionar um evento e a sua representação. Desta forma, a noção de transformação, intrínseca à composição do texto narrativo, atribui ao discurso narrativo a capacidade de gerar significados. Todorov (1966/1973) acrescenta às temporalidades próprias dos personagens, duas outras que pertencem a um plano diferente: o tempo da enunciação, ou seja, da escritura; e, o tempo da percepção, o da leitura. O tempo da enunciação torna-se um elemento literário, a partir do momento em que é introduzido na história, como no caso em que o narrador fala de sua própria narrativa, do tempo que tem para escrever ou para contá-la. 0 tempo da leitura é um tempo irreversível que determina a percepção do conjunto. Tempos "para contar" e "para ler", dois tempos que se unem na produção do texto narrativo dentro de uma psicoterapia de orientação psicanalítica.

\section{Método}

Delineamento de estudo de caso único (Yin, 2001), desenvolvido ao longo de um ano no setting psicoterápico. A unidade de análise principal foi o caso em questão - o adolescente com sintoma na alfabetização, dificuldades de leitura e de aquisição da linguagem escrita. A subunidade de análise são as narrativas produzidas em formato de raps e músicas com suas repetições. 


\section{Participante}

Um adolescente, D., 13 anos, institucionalizado desde seus dois anos, com sintoma de não aprendizagem da leitura e da escrita, não alfabetizado, selecionado a partir dos seguintes critérios: três repetições da primeira série; a não apresentação de desvios de ordem neurológica, intelectual ou psicolinguística; e a participação em intervenções psicopedagógicas que resultaram sem sucesso. D. foi selecionado dentre os pacientes encaminhados para tratamento psicoterápico à Clínica Escola do Curso de Psicologia da Universidade Federal do Rio Grande do Sul.

Histórico familiar: mãe morta, pai desconhecido, e uma irmã, também institucionalizada. Histórico social: estudava em uma escola da rede municipal de ensino; participava como letrista e cantor de um grupo de rappers na escola e de um grupo de dança de rua. Características do adolescente D.: um rapaz comunicativo que gostava de conversar e contar suas histórias sobre música, suas performances de street dance, suas conquistas amorosas, e sua esperteza. Questões de tratamento do paciente D.: dificuldades recorrentes na alfabetização e condutas de furto e mentiras na escola; problemas de relacioamento na instituição; e, principalmente, um desconhecimento sobre sua origem parental.

\section{Instrumentos e material}

O material empírico clínico das sessões terapêuticas realizadas com o paciente $D$. ao longo de um ano de tratamento, todas registradas em gravador digital. Neste período foram totalizadas um número de quarenta e quatro sessões terapêuticas e sessenta e sete produções escritas e orais em forma de músicas e raps, realizadas conjuntamente com o pesquisador-terapeuta. As gravações das sessões foram transcritas concomitantemente ao percurso terapêutico como recurso para registrar as produções musicais e textuais ocorridas nas sessões e para disponibilizá-las ao paciente e ao terapeuta na medida em que eram rememoradas.

0 adolescente, bem como seu responsável institucional, assinou o Termo de Consentimento Livre e
Esclarecido para atender aos critérios de pesquisa com seres humanos. A tese foi aprovada pelo Comitê de Ética da Universidade Federal do Rio Grande do Sul (UFRGS): n² 2005443.

\section{Procedimentos de análise do estudo}

O estudo de análise estrutural das composições narrativas incidiu sobre um conjunto de nove narrativas as quais foram compostas em formato de músicas e raps selecionadas da produção total de 67 músicas compostas em formato de 32 raps e 34 músicas criadas e/ou cantadas no percurso deste um ano de psicoterapia. Critério de seleção: tempo total dividido do tratamento por meses; a cada dois meses foram selecionadas duas composições, exemplos destes períodos e com maiores índices de ocorrência. Esta análise objetivou verificar se estas nove composições caracterizavam-se ou não de forma narrativa. A partir desta análise definiuse o tipo de sintaxe narrativa encontrada (Todorov, 1968/1971; 1969/1982; 1971/2003).

\section{Resultados e discussão}

Apresenta-se, a seguir, os resultados da análise estrutural (Todorov, 1971/2003) do conjunto de nove composições em formato de raps e músicas selecionadas a partir das produções do paciente D., ao longo do processo terapêutico. Objetivouse verificar se as composições criadas caracterizaram-se como narrativas e se as mesmas apresentavam algum padrão na sintaxe narrativa no que se refere ao desenvolvimento da intriga. 0 exame da estrutura das narrativas produzidas no contexto clínico possibilitou explicitar a recorrência do sintoma de um adolescente que encontra dificuldades em aprender a escrever e compreender a linguagem escrita.

A análise proposta por Todorov (1971/2003) proporciona detalhar o texto narrativo na disposição de seus ciclos, o que se torna bastante produtivo para acompanhar o trabalho de composição de narrativas que se produzem repetidamente, ao longo do tratamento do caso em questão. Para Todorov (1968/1971), o estudo da análise da histó- 
ria, na descrição das ações desenvolvidas, define que a intriga mínima completa consiste na passagem de um equilíbrio para outro. A composição narrativa padrão (o cânone narrativo) caracteriza-se por iniciar por uma situação estável (inicial), a qual uma força qualquer vem perturbar. Disso resulta um estado de desequilíbrio, sobre o qual incide a ação de outra força com sentido contrário, a fim de restabelecer o equilíbrio. Esse segundo estado de equilíbrio é semelhante ao primeiro, embora os dois nunca sejam idênticos. Consequentemente, há dois tipos de episódios numa narrativa: aqueles que descrevem um estado (de equilíbrio ou de desequilíbrio); e os que descrevem a passagem de um estado para outro.

No modelo da análise da sequência narrativa, Todorov (1973, in Viera 2001) decompõe o texto em cinco macroproposições. Para cada ação distinta da história corresponde uma proposição (Pn) e esta constitui a unidade de análise mínima. A primeira (Pn1) define a situação estável inicial e caracteriza o momento anterior ao processo narrativo propriamente dito. A segunda ( $\mathrm{Pn} 2)$ corresponde a uma força que vem perturbar o equilíbrio inicial e marca o início do processo. A terceira $(\mathrm{Pn} 3)$ é o estado de desequilibro resultante e corresponde ao processo em si. A quarta $(\mathrm{Pn} 4)$ corresponde à função que fecha o processo através de uma força em sentido inverso que vem a restabelecê-lo. E a quinta (Pn5) é o resultado final, considerado como estado final que define um novo equilíbrio estabelecido, diferente do primeiro.

Em síntese, os cinco estados são assim representados na exposição das nove narrativas:

Pn1: estado inicial (antes do processo) $=$ estado de equilíbrio inicial

Pn2: função que abre um processo (início do processo) $=$ função perturbadora do estado de equilíbrio

Pn3: processo propriamente dito $($ processo) $=$ estado de desequilíbrio resultante
Pn4: função que fecha o processo (fim do processo) = força contrária para restabelecimento do equilíbrio

Pn5: resultado - estado final (após o processo) = novo estado de equilíbrio

As nove composições dispostas abaixo são analisadas duas a duas por seus nomes. Estas exemplificam a produção narrativa de cada bimestre do tratamento e foram agrupadas por temas que se repetiram em cada período. 0 conjunto compõese da seguinte maneira:

- composições do primeiro bimestre do tratamento psicoterápico: música "Ontem tive um sonho" e o rap "Acordo de manhã", que contemplam os temas sonhar - acordar;

- composições do segundo bimestre: rap "Negô Drama" e o rap "Ontem um menino", que trazem o tema morrer/sobreviver - esperança;

- composições do terceiro bimestre: rap "Alma Gêmea" e o rap "Mãe”, sobre o tema: duplo - mãe;

- composições do quarto bimestre de tratamento: o rap "Eu não sou delinqüente" e a música "É preciso saber viver", sob o tema transgredir - viver/sofrer; e,

- composição do quinto e último bimestre: rap "Rap da Vida", tema vida.

Ao considerarmos o conjunto de nove composições musicais (ver anexo A) realizadas pelo paciente D., na soma de todas as repetições de cada uma delas, foram registradas 64 narrativas, num total de 44 sessões de psicoterapia psicanalítica.

As composições 1 e 2 , conjuntamente, foram repetidas treze vezes: 7 a primeira, e 6 a segunda. Deste total, duas $(15,38 \%)$ quatro $(26,66 \%)$ desenvolveram-se até a segunda proposição $(\mathrm{Pn} 2)$, quatro $(30,76 \%)$ até a terceira proposição $\mathrm{Pn} 3$ e sete $(53,84 \%)$, até a quarta proposição $\mathrm{Pn} 4$, constituindo-se em ciclos incompletos, conforme mostrado na Figura 1. 
Figura 1. Percentagens referentes à evolução do ciclo narrativo: composições 1 e 2.

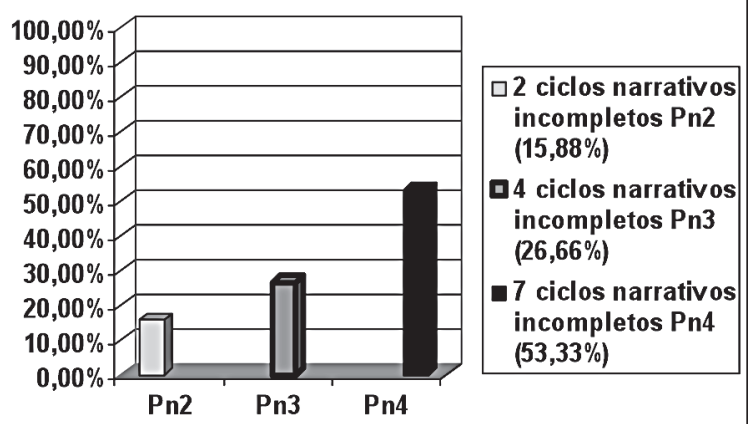

As composições 3 e 4 somam vinte e cinco reproduções: a terceira repetida 16 vezes e a quarta, 9. Deste total, nove (36\%) desenvolveram-se até a terceira proposição $\mathrm{Pn} 3$, quatro $(16 \%)$ até a proposição Pn4; e doze (48\%) até a proposição Pn5. A Figura 2 evidencia esta relação.

Figura 2. Percentagens referentes à evolução do ciclo narrativo: composições 3 e 4 .

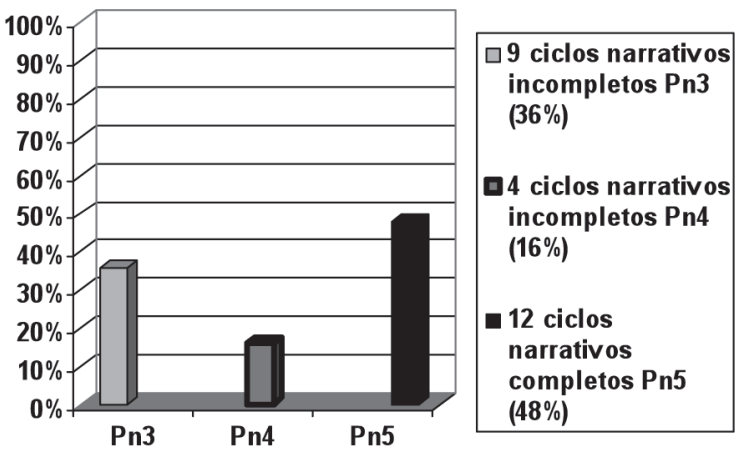

As composições 5 e 6 somam 10 repetições: 5 vezes cada uma. Destas, 4 (40\%) desenvolveram-se até a terceira proposição (Pn3), uma (10\%) desenvolveu-se até a quarta proposição Pn4 e cinco (50\%), até a quinta proposição Pn5, como mostrado na Figura 3.
Figura 3. Percentagens referentes à evolução do ciclo narrativo: composições 5 e 6.

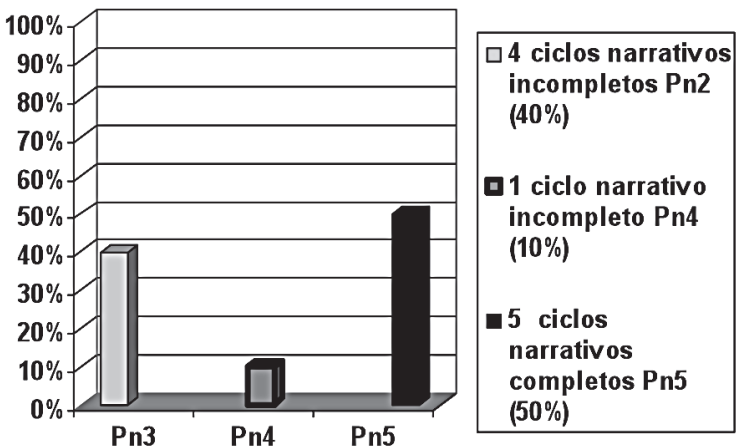

As composições 7 e 8 também foram repetidas 10 vezes: a sétima, 4 vezes e a oitava. Deste total cinco $(50 \%)$ desenvolveram-se até a terceira Pn3, quatro (40\%) até a quarta proposição Pn4 e uma (10\%) até a quinta proposição Pn5. A Figura 4 mostra estas diferenças.

Figura 4. Percentagens referentes a cada proposição narrativa: composições 7 e 8.

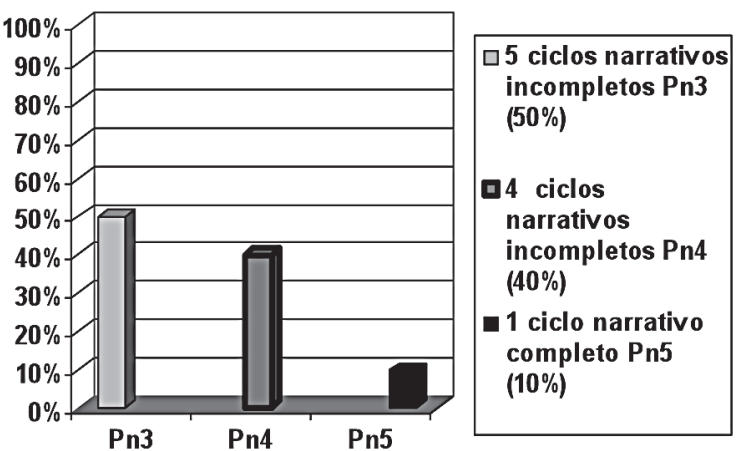

A composição 9 foi repetida 4 vezes, sendo que todas as quatro $(100 \%)$ desenvolveram-se até a proposição Pn5, como indicado na Figura 5 . 
Figura 5. Percentagens referentes a cada proposição narrativa: composição 9.

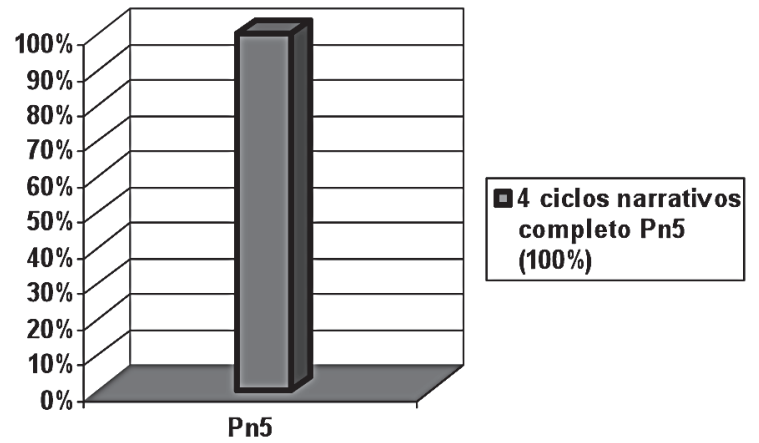

A primeira composição sobre o tema sonhar-acordar, a música "Ontem tive um sonho", marcou o início das composições no tratamento, ao surgir na quarta sessão em novembro de 2005. Completou seu ciclo de sete repetições em junho do ano seguinte. 0 tema surge diretamente expresso na oração inicial: "ontem tive um sonho". Este apresenta "um desejar alguém" através de uma lembrança perdida e restabelecida na forma do sonho que desestabiliza o protagonista ao ver-se sozinho e se questiona sobre o que fazer sem muito direcionamento. 0 segundo exemplo sobre o mesmo tema, o rap "Acordo de manhã", surge, também, na mesma sessão que o anterior, porém reproduzido menos vezes (6) e em períodos mais esparsos: uma no segundo mês de tratamento, uma em janeiro de 2006, quarto mês; e a última, no último mês. Diferentemente da primeira composição, esta apresenta uma sequência de ciclos que se iniciam com "um sujeito que acorda", já não está mais sonhando e afirma-se como alguém que vence: "eu sou um negô de vitória". As duas composições apresentam o protagonista, o agente da ação, na primeira pessoa em dois tempos diferentes, passado e presente: "Ontem, eu tive um sonho..."; "Acordo (hoje) de manhã, boto a cara...". As proposições que se seguem a estes estados iniciais e que desequilibram a situação inicial lançam o protagonista em duas situações: aquele que sonha com um amor, perdido, não sabe o que fazer; e, aquele que acorda e enfrenta a realidade que mostra para ele que seus amores já estão com outros, mas que não tem como não responder a ela. 0 resultado destas duas realida- des, como estados de estar no mundo, ou seja, destas duas situações de desequilíbrio, posicionam o protagonista de forma diferente diante do conflito: o que sonha fica num estado de desorientação, não sabe o que fazer; e o que se depara com a realidade, responde a ela numa tentativa de esquecê-la. Ambas as composições narrativas do período inicial do tratamento não atingem ciclos completos (Pn5), embora apresentem algumas orientações para um novo estado que pode se tornar diferente do inicial. Ao sonhador, darse conta de que estava sonhando, ao que acor$\mathrm{da}$, tentar vencer. Duas soluções que levariam a enfrentar por si as situações que se apresentam: abandono ou perda de alguém; dois verbos que as anunciam: poder e ser. Na primeira composição: "comigo ninguém pode", na segunda, "Eu sou um negô de vitória".

A terceira e quarta composições tematizam o morrer/sobreviver e a esperança, exemplificam produções do quarto mês de psicoterapia. Especificamente, o rap Negô Drama (ver exemplo análise, Anexo B) obteve o maior índice de ocorrências dentre todas as nove analisadas. Repetiu-se dezesseis vezes entre os meses de janeiro e outubro. Neste fluxo de repetições, somente no mês de maio foram nove ocorrências. Os ciclos narrativos destas 16 repetições compuseram-se, predominantemente, de formas completas. É uma "história real", conforme o paciente e narra a história de um homem que, apesar de ser um cidadão comum, é confundido com um transgressor ou um traidor (não fica claro) que acaba por ser morto pelos próprios pares. Na situação inicial (Pn1), o narrador apresenta o protagonista através de seus qualificativos, numa situação cotidiana: "foi num domingo de sol, ele saiu de manhã (...) ele era um cara maneiro (...) ele era funkeiro". Esta situação é interrompida abruptamente com a morte do personagem. Todo o trabalho narrativo que se segue tem o propósito de explicar este fato que parece surpreender o narrador. 0 desequilíbrio que resta desta situação gera o conflito a ser solucionado que aparece em forma de paradoxo: como um homem comum, trabalhador, com família constituída e que curte música de rap é morto pelos próprios companheiros. As tentativas de retomar o equilíbrio nesta narrativa circulam, gra- 
dativamente, por explicações ao redor de classe social, condição socioeconômica, discriminação, transgressão, destino, solidão e que, finalmente, se tornam diretamente articuladas nas duas apresentações finais da narrativa (agosto e outubro do ano de 2006). As proposições que compõem estes ciclos (Pn4) trazem transformações à oração inicial que apresenta o conflito "ele era funkeiro, mas era pai de família" e que vai organizando o contar da história da origem do personagem, sua condição de inserção social extravasada no seu gosto pela música rap como força de expressão e que o confronta com uma realidade discriminatória. O ciclo se completa em Pn5 com o explicitar da trama que em si já é um drama na própria designação do protagonista "negô drama". O narrador repassa a história de luta do personagem principal para sobreviver e que, para fazê-lo, precisa estar consciente de sua própria condição e buscar o reconhecimento do outro, sem corromper-se: "sozinho você não é ninguém". Aparece um forte conteúdo que designa uma origem e que poderia determinar um destino do qual o protagonista não consegue escapar.

Conjuntamente ao rap "Negô drama", que explicita a crueza de "uma história real", o paciente compõe o rap "Ontem um menino" que traz um contraponto à morte, a esperança. Esta foi repetida nove vezes ao longo do tratamento e, diferente da anterior, mas similar às duas primeiras na forma de apresentação em primeira pessoa, o narrador descreve a condição de um menino que vai crescer. Sua sequência de apresentações é composta por ciclos incompletos (Pn3) em todas as suas repetições, chegando somente até a fase de desequilíbrio da situação inicial. A situação inicial é desequilibrada ( $\mathrm{Pn} 2)$ quando o narrador ouve de alguém, provavelmente um homem que já foi menino, que não precisa temer o futuro. É preciso acreditar que a sua situação, que não fica explicitada qual é, vai se modificar se ele acreditar na capacidade do homem de transformar. O tempo verbal utilizado é o futuro e os verbos: passar, desesperar, sonhar, fazer, poder. A temática desenvolvida é a "esperança" como uma tentativa de acreditar em um futuro que depende de fé na vida, mas também da ação conjunta de pessoa, algo já afirmado ao final do rap anterior,
Negô Drama. Como os ciclos narrativos chegam somente ao estado de desequilíbrio ( $\mathrm{Pn} 3)$, o que se anuncia é a necessidade de fazer algo, mas que não é complementado nem como e nem no tempo de sua realização. Apesar da sequência narrativa "Ontem um menino" não formar ciclos completos, expressa como as demais as tentativas do paciente de compreender a sua história de origem pautada por fatos desconhecidos, perdas de figuras parentais e permeada pelo auxílio de outras pessoas que ocuparam lugares importantes na sua vida.

As duas primeiras composições, ao colocarem o personagem principal de um estado de sonho para o de acordado, chegam a ciclos (Pn4) que tangenciam uma possível resolução para o conflito inicial; as outras duas, que colocam o questionamento do protagonista sobre o morrer, tentar sobreviver e ter esperança, fazem com que somente o rap Negô Drama, que atinge ciclos completos (Pn5), traga um desabafo do protagonista na busca de uma esperança de explicar a sua condição. Condição, ainda, frágil, pois o passado expresso na composição "Ontem um menino me falou que hoje é a semente do amanhã" atinge somente ciclos incompletos (Pn3), sem o protagonista-paciente compreender como é possível fazer de hoje um amanhã neste momento do percurso terapêutico.

O tema duplo-mãe é trazido nas duas composições do terceiro bimestre do tratamento através da música "Alma Gêmea" e do rap "Mãe". A primeira destas foi composta entre abril e novembro de 2006, com cinco repetições de ciclos incompletos ( $\mathrm{Pn} 2)$, intercaladas por um que restabelece o equilíbrio (Pn4). Há predomínio de microproposições que apresentam uma força que perturba o equilibro inicial e que dá partida ao processo (Pn2) sem continuidade do mesmo. 0 tema estampa os duplos, o que, aliás, foi uma forma recorrente do paciente $\mathrm{D}$. se expressar: viver-morrer; amar-morrer; amantes-irmãos. A temática narrada é acompanhada de relatos do paciente quanto às suas perdas constantes na vida: pais, amigos, componentes da instituição em que vive e de onde advém; e de seu constante questionamento sobre a morte. A proposição inicial da composição 
"Alma Gêmea" aparece na forma impessoal, no duplo amante-irmão, quase como um delírio onírico (Pn1). O desequilíbrio desta situação inicial vem expresso pela oração "estou morrendo de vontade de você" que coloca o personagem numa posição passiva de lamento por uma perda de um duplo ou de um complemento, o que não fica esclarecido nestas duas primeiras apresentações ocorridas. É somente na terceira recorrência, cinco sessões após esta, que haverá um desenrolar da ambiguidade, não ainda definida quanto a quem ocuparia o lugar de uma alma gêmea, mas somente para definir do que se trata e para lançar o personagem no limite entre o viver o morrer. 0 rap Mãe finaliza a apresentação deste tema e teve sua primeira aparição na vigésima quarta sessão, uma após a segunda repetição do rap "Alma Gêmea". Todas as cinco recorrências do rap "Mãe" foram caracterizadas por ciclos completos (Pn5). A proposição inicial apresenta o protagonista em condição de total desamparo. Utilizando a primeira pessoa e o tempo verbal passado, o narrador rompe este equilíbrio, indicando que seu sofrimento está relacionado à morte de um amigo e, principalmente, à de sua mãe (Pn2). Esta perda é uma situação que é dada e que gera um pedido de desculpas sem uma razão clara, e um sentimento de solidão. Ressurge o questionamento sobre o viver e de como a vida se apresenta tênue para ele (Pn3). As tentativas de restabelecer esta situação vão ser expressas nas três repetições do rap ocorridas em junho, agosto e finalizadas em outubro, respectivamente, vigésima oitava, trigésima quarta e quadragésima sessões, quase ao final do tratamento. Este novo estado de equilíbrio ( $\mathrm{Pn} 4)$ é marcado pela afirmação de que a vida é assim, incerta, e que a morte é uma de suas conseqüências. E finaliza a sequência narrativa (Pn5) com a noção de complementaridade do ciclo vital. Há a transformação da situação inicial de insegurança e desamparo em certeza para o próprio sujeito, de que "minha mãe para mim, é muito bacana".

O rap "Eu não sou delinquente” e a música “É preciso saber viver" são as duas composições que exemplificam a produção do quarto bimestre de tratamento e trabalham sobre o tema transgredir - viver/sofrer. Especificamente, o rap "Eu não sou delinquente" teve quatro incidências, to- das caracterizadas por ciclos incompletos (Pn4). A proposição inicial remete a um protagonista apaixonado e sonhador (Pn1). Surge novamente a temática apresentada na composição "Ontem tive um sonho". O que vem a interromper esta "sonolência amorosa" ( $\mathrm{Pn} 2)$ é a figura de um personagem que representa autoridade, o guarda. A partir daí, o protagonista se vê obrigado a responder a este estado de confrontamento (Pn3), o que é feito pela negativa: "eu não sou delinquente... eu não sou vagabundo... sou um cara carente" que somente sonhava. Uma apresentação de si que acontece duas vezes pelo não e que se conclui em um estado de falta. A resolução deste conflito de confrontamento, em busca de um novo estado de equilíbrio ( $\mathrm{Pn} 4)$, é tentada através do pedido de complacência para com aquele que se enamora. Ao mesmo tempo, em consonância com seu estado de apresentação "carente", o protagonista aparece numa entrega ao outro. Interpretarmos os pontos levantados ao final da resolução narrativa, que não atinge totalmente um equilíbrio (Pn5), como aspectos significativos do adolescer: apaixonar-se e submeter-se, como também deflagrar a busca do paciente pelo reconhecimento de si em relação aos outros. 0 segundo exemplo do desenvolvimento desta mesma temática é manifestado na música "É preciso saber viver", de domínio público. Entremeada de ciclos narrativos incompletos e um completo, foi repetida seis vezes com uma distribuição mais equitativa ao longo do tratamento, no período de maio a outubro do ano de 2006. Quase todas as macroproposições são entremeadas recorrentemente pela frase inicial: "é preciso saber viver". As repetições do tema "saber viver" trazem um imperativo que se coloca como uma necessidade que se impõe ao protagonista: conteúdo recorrente nas narrativas construídas pelo paciente, viver-vida, penoso para o paciente $D$. uma vez que vem colado à idéia de morte. A situação inicial (Pn1) aparecer pela insígnia "é preciso saber viver" e gera um desequilíbrio difícil de ser resolvido ( $\mathrm{Pn} 2)$, pois a vida se apresenta como algo temível, ilusório, e que causa sofrimento, na medida em que há tropeços e obstáculos muitas vezes até nem percebidos. Há uma insistência na repetição da trama que não passa de um estado de desequilíbrio $(\mathrm{Pn} 3)$ e somente uma vez virá a ser transformado 
numa tentativa de resolução $(\mathrm{Pn} 5)$ que retoma a possibilidade de morte e convida o interlocutor a ser complacente com ele. Esta intriga, ao se resolver somente uma vez, não traz muitas alternativas para o paciente, na medida em que suas incertezas quanto aos laços familiares e às possibilidades de amizade como solução para a sua constate solidão o lançam aparentemente à deriva de um destino. Com um apelo constante a um saber sempre desconhecido e dialético, o protagonista volta à necessidade de um saber sobre o viver. 0 retorno sempre expresso pela máxima "é preciso saber viver" evidencia a busca constante do paciente no sentido de se apropriar de um conhecimento de si que possa ser referendado por alguém. É necessário que a vida se torne menos sofrida, uma vez que o paciente foi privado de sua família de origem na literalidade de sua situação de órfão. Ele, ainda, construía uma possível explicação para suportar este abandono.

O "Rap da Vida" completa a análise estrutural das nove composições do paciente D. que exemplificam as produções temáticas desenvolvidas no percurso terapêutico. Surgiu ao final do processo, entre outubro e novembro de 2006 e, assim, designado por "resumir" em seu tema vida, o rap da história de D., narrada ao longo da psicoterapia. Sempre produzido em ciclos completos (Pn5) e narrada na primeira pessoa, a proposição inicial (Pn1) apresenta o protagonista no seu sintoma "tava na escola, não queria estudar"; no seu desejo de ser "eu só quero é ser feliz"; e de seu empenho e necessidade de transformar. 0 que perturba essa situação ( $\mathrm{Pn} 2)$ são os questionamentos e o enfrentamento que o próprio protagonista assume com a sua realidade: analfabeto, institucionalizado, pais desconhecidos, possibilidade de uma vida desviante. 0 que resta deste conflito é um desequilíbrio real $(\mathrm{Pn} 3)$ de quem nada tinha e que o faz "rebolar" para transformar o que os outros dele pensavam para tornar-se alguém "respeitado". Através da composição deste rap surge a possibilidade de mudar essa condição na direção de tornar-se alguém capaz de lutar pela sua vida. 0 novo estado de equilíbrio (Pn5) o lança na prospecção de uma vida adulta que o faça sentir-se realizado e projetado. Essa narrativa reconstrói e conclui temas já presentes em suas outras pro- duções. A narrativa o Rap da Vida possibilitou para este adolescente a (re) construção de uma história de si.

\section{Síntese dos resultados da análise estrutural}

A análise das 64 narrativas dispostas na enunciação das nove composições acima analisadas, variaram ao longo de suas sucessivas repetições quanto à disposição de suas macroproposições. Os temas recorrentes que foram trabalhados no decorrer de um ano de psicoterapia psicanalítica como: sonhar - acordar; morrer/sobreviver - esperança, duplo - mãe; transgredir - viver/sofrer; vida; estavam diretamente relacionados a significação que o sintoma de não aprendizagem da linguagem escrita assumiu no decorrer da história de vida do paciente $D$.

Destas sessenta e quatro narrativas, seis chegaram a um estado de desequilíbrio (Pn2), dezoito terminaram em estado de desequilíbrio (Pn3), dezoito esboçaram a tentativa de reconstituição do estado de equilíbrio (Pn4) e vinte e duas delas apresentaram estado de equilíbrio restabelecido, demonstrando ciclo narrativo completo (Pn5), conforme pode ser visto na Figura 6, abaixo.

Figura 6. Percentagens referentes a cada proposição narrativa: conjunto das composições.

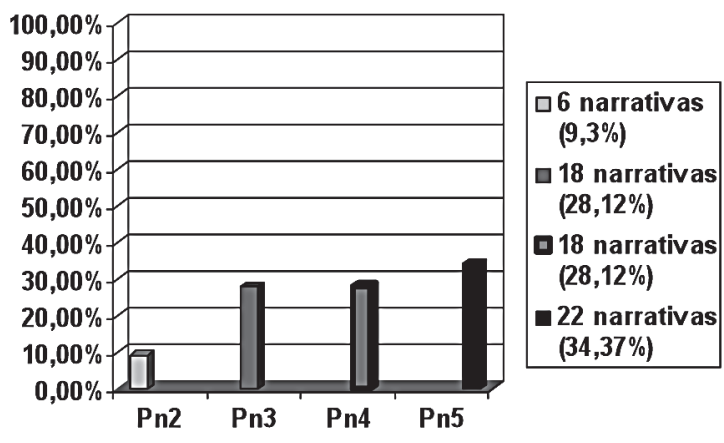

Em termos percentuais, $65,54 \%$ das narrativas analisadas constituíram um ciclo narrativo incompleto (Pn2, Pn3 e Pn4), e 34,37 \% das narrativas desenvolveram um ciclo narrativo completo (Pn5). Estes percentuais podem ser observados na Figura 7. 
Figura 7. Percentagens referentes à evolução do ciclo narrativo: conjunto das composições.

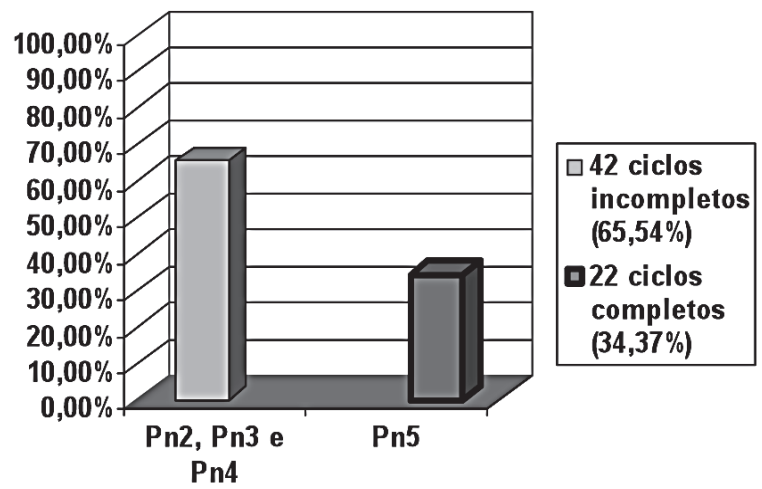

\section{Discussão dos resultados} da análise estrutural

Uma primeira conclusão, a partir da análise das 64 narrativas, aponta que: as composições produzidas ao longo do tratamento, em formato de rap e músicas, constituem-se como narrativas. Conforme a definição canônica do texto narrativo (Todorov, 1968/1971), os textos narrativos caracterizam-se por apresentarem uma situação inicial que sofre transformações ao longo do processo de narratividade e resulta em um estado final que encontra um novo equilíbrio, diferente do primeiro apresentado.

Observar-se que, dentre o conjunto das nove narrativas construídas neste processo de tratamento, cinco $(55,56 \%)$ enquadram-se como ciclos narrativos incompletos ( $\mathrm{Pn} 3$ e Pn4) e quatro $(44,44 \%)$ atingem o formato de ciclos narrativos completos. Encontrou-se uma tendência para sequências de ciclos incompletos (Pn3 e Pn4). Isto indica que a composição narrativa em psicoterapia é delimitada pelo próprio contexto, ou seja, o tempo de construção do próprio texto narrativo na clínica acompanha o movimento do trabalho de elaboração do sintoma. Em síntese, as nove composições analisadas constituem-se como narrativas que em sua sintaxe (Todorov, 1971/2003) evidenciam, no mínimo, duas situações distintas que apresentam entre elas uma relação de transformação.
Uma segunda conclusão: o texto narrativo produzido em sessão caracteriza-se pela repetição ao longo de seu processo de composição. Como já indicado anteriormente, cada uma das nove narrativas foi repetida, em média, cinco vezes. $\mathrm{E}$, algumas destas ocorriam dentro da mesma sessão, como por exemplo, o rap Negô Drama que foi repetido nove vezes no sétimo mês de tratamento e quatro na segunda sessão deste mesmo mês. Encontra-se em Todorov (1968/1971), a explicação de que o encadeamento global de uma narrativa, ou seja, a intriga, pode estar disposta em mais de uma sequência narrativa, como tentativas de reconstituir a articulação entre os personagens e suas ações na cadeia de sucessão da narrativa. Embora, o autor afirme que nem toda sequência corresponderia sempre a um mesmo conto: uma sequência pode ser reproduzida em outros contos que tenham a mesma intriga; ou, um mesmo conto pode conter diversas sequências. 0 contexto psicoterápico torna-se o "lugar" da narratividade de si para aquele que faz sintoma na aquisição do conhecimento da linguagem escrita. Ao incidir sobre a injunção das repetições das composições narrativas com o desdobramento da produção sintomática, proporciona o explicitar do próprio processo de elaboração terapêutica da conflitiva apresentada pelo paciente. 0 uso de narrativas no tratamento de pacientes com sintomas de não escrita torna explícito o conflito, consequentemente, facilita o trabalho de análise direta deste; uma vez que com a repetição das sequências narrativas, o conteúdo destas tende a ser elaborado e, consequentemente, a ser concluído em ciclos completos.

Ao examinarmos os dados percentuais mostrados acima, quanto aos índices de repetição e número de ciclos completos encontrados em cada uma das composições narrativas, podemos observar, por exemplo, que no processo de elaboração ocorrido nas repetições no rap Negô Drama, dezesseis vezes no total, quatro destas constituíramse de ciclos narrativos incompletos (Pn4) e doze destas de ciclos completos (Pn5). Esta narrativa trabalhou o conteúdo temático morrer/sobreviver-esperança. Outro exemplo é o rap Mãe que foi repetido cinco vezes na forma de sequências de ciclos completos (Pn5) e trabalhou o conteúdo 
temático duplo-mãe. Observamos que estas duas narrativas explicitam os motivos que podem ter levado o paciente D. a sintomatizar no aprender da linguagem escrita, na forma de um se negar ao saber: como explicar, viver e transformar um desconhecimento sobre a história de sua origem. $\mathrm{E}$, no percurso final do tratamento, a composição do rap da Vida, repetido quatro vezes, todas dispostas em ciclos completos (Pn5), demonstra o efeito das construções que o tratamento produziu em $D$. ao re-construir sua história de vida e ao fazê-lo prospectar seu futuro.

Uma terceira conclusão a indicar, em consonância com os príncipios da clínica psicanalítica quanto aos aspectos repetição e elaboração (Freud, 1914), como os efeitos da prática clínica: a existência de um padrão, nas narrativas de ciclos completos, em relação a como a intriga é desenvolvida. Tal organização indicaria ao terapeuta o modo como o paciente lida com o seu próprio sintoma.

De acordo com a fórmula condensada da intriga proposta por Todorov (1968/1971), as quatro narrativas que atingiram ciclos completos (Pn5), os raps "Negô Drama", "Mãe", e o "Rap da Vida" e a música "É preciso saber viver", enquadram-se no modelo proposto pelo autor (p.71), exposto abaixo:

$\begin{array}{ll}\Gamma \text { incomoda } X & \Gamma \text { não incomoda mais } X \\ Y & X \text { ataca } Y \rightarrow Y \\ L_{\text {tem uma }} & L \text { não tem mais } \\ \text { imperfeição } & \text { esta imperfeição } \\ \text { interna } & \end{array}$

Nos raps "Negô Drama" e "Mãe", os protagonistas apresentam-se com imperfeições: um, funkeiro e desviante, envolvido com transgressões; e outro, transeunte, drogado e recolhido a instituicionalização. Ao se depararem com a morte (ou própria, no primeiro rap, ou da mãe, no segundo), fazem com que o narrador submeta-os a um processo moral, ou na forma de um questionamento sobre as condições sociais das camadas mais carentes, ou de um pedido de perdão, a fim de transformálos. Esse processo ao qual o protagonista se vê impelido traduz para Todorov (1971/2003) dois aspectos fundamentais para a análise estrutural da narrativa: sucessão e transformação. Para o autor, a noção de transformação é a essência da narrativa, pois é através dela que o narrador articula os fatos produzindo significações e torna o discurso, um discurso narrativo.

Ao definirmos um parâmetro de construção da intriga no texto narrativo composto pelo paciente D., segundo o modelo todoroviano, chegamos a dois pontos importantes no trabalho clínico: a dinâmica do próprio paciente de funcionar em seu sintoma de não alfabetizar-se, e a dinâmica do próprio tratamento psicoterápico que se utiliza do texto narrativo. Esta última, ao pautar-se por sucessivas construções narrativas sobre os temas, auxilia o trabalho clínico através das sucessivas repetições deste sintoma, encontradas como conteúdos nas histórias contadas.

Uma quarta conclusão que a análise propicia e que se opera a partir das outras acima colocadas: o uso do texto narrativo pode tornar-se um instrumento de intervenção e análise no tratamento de orientação psicanalítica de adolescentes que produzem sintoma no processo de aprender a linguagem escrita. Primeiro, a composição do texto narrativo compartilhada na relação transferencial entre um paciente-narrador e uma terapeutatranscritora, e explicita pela análise estrural, demostra o reposiciona o sujeito em relação ao seu próprio sofrimento psicológico: um não saber sobre sua origem que aparece num não saber sobre a linguagem escrita. Ao narrar para o terapeuta (suas) histórias, vão produzindo-se arranjos que o paciente-narrador compõe entre os personagens e suas ações e que fazem mover os conteúdos inconscientes que produziram o sintoma. Segundo, as composições narrativas, que em suas sequências vão se modificando de ciclos incompletos para ciclos completos, indicam os resultados do trabalho clínico sobre o sintoma, na medida em que proporcionam a elaboração de conteúdos retidos, em outras significações possíveis. E este movimento torna-se um indicador eficaz dos resultados do tratamento. 


\section{Referências}

Araújo, A. T. da S. (2002). A clínica e os problemas na aprendizagem. Psicologia: Teoria $e$ Prática, 4(1), 13- 20.

Bastos, M. B. (2006, november). Transmissão da psicanálise a educadores: quando a circulação da palavra implica um fazer-dizer. In M. C. M. Kupfer, L. de Lajonquière, Rinaldo Voltolini (Chair). VI Colóquio Internacional do LEPSI, São Paulo, Brasil.

Beran, E., Unoka, Z. (2005). Construction of selfnarrative ia a psychoterapeutic setting. An analysis of the mutual determination of narrative perspective taken by patient and therapist. In U. M. Quasthoff \& T. Becker (Eds), Narrative Interaction (pp. 151-167). Amsterdam, Netherlands: John Benjamins Publishing Company.

Cordié, A. (1996). Os atrasados não existem. Porto Alegre, Brasil: Artes Médicas.

Cordioli, A. V. (Ed.). (2008). Psicoterapias: Abordagens atuais. ( $3^{\mathrm{a}}$ ed.). Porto Alegre, Brasil: Artmed.

Deakin, E.K., Nunes, M.L.T. (2008). Investigation in child psychotherapy: a review. Rev. Psiquiatr. Rio Gd. Sul [online], vol.30, n.1, suppl. [cited 2009-11-13], pp. 0-0. Available from: <http://www.scielo.br/scielo.php?script=sci_ arttext\&pid=S0101-81082008000200003\&lng $=e n \& n r m=i s o>$. ISSN 0101-8108. doi: 10.1590/ S0101-81082008000200003. ACESSO EM 24/09/09

Degenszajn, R. D., Roz, D. P., Kotsubo, L. (2001). Fracasso escolar: uma patologia dos nossos tempos? Pediatria, 23(1), 106-13.

Ducrot, O., Todorov, T. (1998). Dicionário Enciclopédico das Ciências da Linguagem (A.K Miyashiro, J. Guinsburg, M.A.L. Barros \& G.G. Souza, Trans.). São Paulo, Brasil: Editora Perspectiva.
Farias, F. R. de. (2007). 0 fracasso escolar no cenário das patologias da contemporaneidade. Arquivo Brasileiro de Psicologia, 59(2), 232-244.

Freud, S. (1976). Recordar, repetir, e elaborar (Novas recomendações sobre a técnica da psicanálise II). (M.A.M. Rego, Trans.). In J. Salomão (Ed.), Edição standard brasileira das obras completas de Sigmund Freud (vol. 12, pp. 193-203). Rio de Janeiro, Brasil: Imago. (Original work published in 1914).

Jardim, A. P., Oliveira, M. Z. e Gomes, W. B. (2005). Possibilidades e dificuldades na articulação entre pesquisa e psicoterapia com adolescentes. Psicologia: Reflexão e crítica, 18(2), 215-224.

Kristeva, J. (1980). O texto fechado. (I. Gonçalves \& M. Barahona, Trans.) In R. Barthes (Eds.), Lingüística e Literatura. (pp. 143-170). São Paulo, Brasil: Martins Fontes. (Original work published in 1967).

Kristeva, J. (2003). História da Linguagem. (M.M. Barahona, Trans.). Lisboa, Portugal: Edições 70. (Original work published in 1969).

Kupfer, M.C.M. (2002). A escrita na clínica psicanalítica. III Colóquio Internacional do LEPSI, São Paulo, Brasil.

Paín, S. (1987). A função da ignorância. Porto Alegre, Brasil: Artes Médicas.

Reis, C., Lopes, A.C.M. (1988). Dicionário de teoria da Narrativa. São Paulo, Brasil: Editora Ática.

Santiago, A. L. B., Castanheira, M. L. (2004, september). Educação, Psicanálise e Saúde Mental: Nova Proposta de Diagnóstico dos problemas escolares. [Abstracts]. In $2^{\circ}$ Congresso Brasileiro de Extensão Universitária Belo Horizonte, Belo Horizonte, Brasil.

Sousa, D. (2004). O mundo do texto e a psicoterapia fenomenológico-existencial. Análise Psicológica, 4(22), 691-704. 
Todorov, T. (1971). Estruturalismo e Poética. (J.P.Paes, Trans.). São Paulo, Brasil: Editora Cultrix. (Original work published in 1968).

Todorov, T. (1973). As Categorias da Narrativa Literária. (M.Z.B. Pinto, Trans.) In R. Barthes (Ed.). Análise Estrutural da Narrativa. Pesquisas Semiológicas. (pp. 209-254). Petrópolis, Brasil: Vozes. (Original work published in 1966).

Todorov, T . (1982). A Gramática do Decameron. (E. Orlandi, Trans.). São Paulo, Brasil: Editora Perspectiva. (Original work published in 1969).
Todorov, T. (2003). Poética da Prosa. (C. Berliner, Trans.). São Paulo, Brasil: Martins Fontes. (Original work published in 1971).

Vieira, A. G. (2001). Do conceito de estrtura narrativa à sua crítica. Psicologia: Reflexão e Crítica, 14(3), 599-608.

Vincent, M. (2006, november). Fracasso escolar - reflexões! In M. C. M. Kupfer, L. de Lajonquière, Rinaldo Voltolini (Chair). VI Colóquio Internacional do LEPSI, São Paulo, Brasil.

Yin, R.K. (2001). Estudo de caso: planejamento e métodos. (D. Grassi, Trad.). Porto Alegre, Brasil: Bookman. 